\title{
A PALAVRA DO ANO É UMA IMAGEM
}

\section{THE WORD OF THE YEAR IS AN IMAGE}

\author{
Greciely Cristina da Costa \\ Universidade do Vale do Sapucaí, UNIVÁS, Pouso Alegre, MG, Brasil
}

\begin{abstract}
Resumo: Anualmente o Dicionário Oxford elege uma palavra como sendo a "palavra do ano". Em 2015, a palavra eleita foi um emoji, ou seja, a escolhida năo foi uma palavra, mas uma imagem. A partir desse fato, com base na perspectiva teórica da Análise de Discurso, visamos compreender, nesse artigo, um modo específico de se estar na sociedade contemporânea na relação com a escrita e com a imagem digital, considerando, sobretudo, que a constituição dos sentidos e dos sujeitos é afetada pela discursividade do eletrônico.
\end{abstract}

Palavras-chave: emoji; palavra; imagem; discurso digital.

Abstract: Every year the Oxford Dictionary chooses a word as the "word of the year". In 2015, the word elected was an emoji, that is, it was not chosen a word, but instead, an image. From this fact, based on the theoretical perspective of discourse analysis, this article aims to understand a specific form of being in contemporary society in the relation with the writing and the digital image, considering especially that the establishment of senses and the subject is affected by the discourse of electronic.

Keywords: emoji; word; image; digital discourse.

"não há transparência, controle nem cálculo que possa apagar o equívoco, a imprevisibilidade e a opacidade" (ORLANDI, 1994, p. 64).

\section{A palavra do ano}

O conceituado dicionário de língua inglesa Oxford elege, anualmente, a palavra do ano. Um júri vota na palavra que mais atraiu o interesse da sociedade em um ano, com base em critérios que, em geral, levam em conta a relevância cultural e o potencial de estabilidade do termo.

Em 2015, oito palavras foram selecionadas, dentre elas, o termo refugiado - que, em Portugal, ganhou o título ${ }^{1}$. No entanto, a palavra eleita foi um emoji, ou melhor, a escolhida não foi uma palavra, mas uma imagem, por ter sido ela a que melhor refletiu o ethos, o humor e as preocupaçóes do

\footnotetext{
${ }^{1}$ O processo de seleçáo criado em 2009 é uma iniciativa da Porto Editora e recebe apoio do Camôes - Instituto da Cooperação da Língua.
} 
ano, segundo o que consta no blog Oxford Dictionaries 2 .

Portanto, a palavra de 2015 é uma imagem. Contudo, não se trata de uma imagem qualquer, mas de uma imagem que está ligada diretamente ao discurso digital pela sua formulação, circulação e constituição (ORLANDI, 2001). Termos que, de modo específico, vinculam-se ao digital já foram eleitos pelo Oxford em anos anteriores como palavras do ano. Em 2013, foi a palavra selfie. Em 2012, GIF, sigla que ganhou o estatuto de palavra, foi incluída no referido dicionário como verbo. Podemos, assim, dizer que o digital se apresenta na base da produção discursiva das palavras que se destacaram ao longo dos últimos anos. Isso porque elas têm em comum a conjuntura sócio-histórica-ideológica que se constitui com o discurso eletrônico.

É preciso observar que esses outros dois termos também se reportam à imagem, seja pela relaçáo que ela mantém com o sujeito, no caso de selfie, numa referência à imagem produzida de si mesmo por câmeras de smartphones ou webcam e frequentemente postada em redes sociais, tais como facebook e instagram; ou pela relação que mantém com um aparato tecnológico, no caso de GIF (Graphics Interchange Format), que nomeia um formato de arquivo gráfico específico, capaz de criar imagens animadas.

O que nos chama a atençáo no caso específico de 2015 é o fato de que, embora a palavra do ano também esteja ligada ao digital, não se trata de uma palavra, mas de uma imagem. A palavra emoji poderia ter sido a eleita, porém foi a imagem a seguir a vencedora: tendo sido considerada a mais usada no mundo no ano de referência.

Da perspectiva da Análise de Discurso, esse fato levanta ao menos três questôes acerca da relação entre linguagem, sociedade e tecnologia. A primeira se refere ao equívoco e aos deslocamentos de sentido produzidos ao se eleger uma imagem como palavra. Ambiguidade, indistinçáo entre uma e outra? A segunda, consequência da primeira, evoca um processo discursivo que é desencadeado pela imagem na articulação com a tecnologia, pois a palavra é substituída pela imagem por um dicionário de língua. Que efeitos de sentido produz essa substituição? E a terceira também coloca o digital no cerne das práticas de escrita atuais que se formulam por meio de uma relação complexa entre a imagem e o modo de significar o mundo, as relaçốes sociais. Como um processo social se manifesta na escrita? Como a interpretação se inscreve aí, produzindo sentidos e sujeitos?

\footnotetext{
2 Anúncio disponível em: <http://blog.oxforddictionaries.com/2015/11/word-of-the-year2015-emoji/>. Acesso em: 30 jul. 2016.
} 
Partindo dessas três questôes, nossa proposta é analisar algumas discursividades, tomando discursividade como a inscriçáo dos efeitos linguísticos materiais na história (PÊCHEUX, 1994), por meio de recortes referentes ao anúncio da palavra do ano, ao verbete emoji do Dicionário Online de Português e à emojipedia. Para isso, filiamo-nos teoricamente na Análise de Discurso, a qual compreende "a ordem da língua tomada como sistema significante em sua relação com a história, considerada materialidade simbólica" (ORLANDI, 1996, p. 27), constituída pela ideologia.

\section{Um gesto político}

De acordo com Pêcheux (1997, p. 179), é "impossível analisar um discurso como um texto, isto é, como uma sequência linguística fechada sobre si mesma [...], é necessário referi-lo ao conjunto de discursos possíveis a partir de um estado definido de condiçóes de produçáo", entendendo produção, salienta o autor, como "remetendo a efeito e condiçôes pelas quais esse efeito é produzido ou náo produzido" (PÊCHEUX, 2011, p. 215). Assim, em termos de condiçóes de produção, é significativo para a análise observar que a escolha de uma palavra de destaque se dá em uma formaçáo social capitalista, em uma conjuntura sócio-histórica-ideológica determinada pelo avanço tecnológico, pela informatização da sociedade, pela mundialização das relaçóes, entre outras, econômicas, financeiras, culturais, de um lado; e, por outro, pelos conflitos armados em vários países em decorrência de racismo, princípios religiosos, questôes políticas das mais diversas.

Em um importante trabalho sobre os chamados espaços linguísticos e seus desafios, Orlandi (2012a) traça um panorama mais amplo dessas condiçóes de produção, mostrando a relação entre o discurso do multilinguismo e a mundialização e seus efeitos na atual conjuntura. Em síntese, retomando o estudo de Carroué, a autora situa que a sociedade hoje é regida por um processo "geo-histórico de extensão progressiva do capitalismo em escala mundial e que é, ao mesmo tempo, uma ideologia (neoliberal), uma moeda (o dólar), um instrumento (o capitalismo), um sistema político (a democracia), uma língua (o inglês)" (p. 7).

Situada nessa conjuntura, a escolha da palavra do ano é promovida por um dicionário de língua, cuja língua não é qualquer uma, é a língua inglesa, a língua justamente do processo de mundialização, da economia, do mercado internacional, da tecnologia. Isso tem efeitos. Além do mais, essa escolha é gerida por uma instituição inglesa de ensino, a primeira 
universidade do mundo anglofônico que ao estar, de certo modo, investida nessa escolha já aponta para a legitimidade e alcance de uma aparentemente simples seleção lexical.

Legitimidade e alcance que, ao mesmo tempo, recaem sobre e acentuam o dicionário como instrumento linguístico que, como tal, junto à gramática, modifica a relação dos falantes com a língua, funcionando no processo de gramatização (AUROUX, 1992) de maneira a produzir e a reproduzir sentidos como evidentes, homogêneos e estáveis, para além da anglofonia. Lembrando que, ao se configurar, assim, em um espaço imaginário de evidências e certitude, mostra-se, também, segundo Nunes (2006), um lugar de observaçáo dos modos de dizer de uma sociedade.

A circulação de discursos sobre a mediação tecnológica das relações sociais em larga escala e o imaginário produzido acerca da tecnologia e sua capacidade de diminuir distâncias, incluir pessoas, dar acesso ao conhecimento e romper limites se justapóem aos interesses que visam ao capital. É nesse ínterim que a palavra do ano explicita um gesto político e intervém nas relaçóes de força e poder; afetando, inclusive, as políticas de língua.

Um gesto político engendrado tanto pela apropriação do termo emoji, pois, em 2013, essa palavra japonesa foi introduzida no dicionário inglês, quanto pela criação de uma espécie de enciclopédia especializada em emojis, a emojipedia. Como analisaremos mais adiante, o modo como se institui e funciona essa enciclopédia reitera a apropriação, cujo efeito é a anglofonização do emoji, a administração de seus sentidos.

Um gesto político ancorado, em certa medida, no discurso eletrônico, uma vez que está em jogo, na seleçáo da palavra do ano, uma imagem digital $^{3}$. O inglês, como ressalta Orlandi (2012a), nas condiçóes atuais, já se apresenta como dominante no espaço digital, como língua franca universal da comunicação e do conhecimento, muito em parte pelo apoio tecnológico. A apropriação, também, de uma imagem digital configura, então, um gesto político de expansão do domínio sobre esse espaço, visto que, na qualidade de imagem, o emoji não seria de domínio linguístico específico.

No tocante ao eletrônico, Dias (2011,) explica:

\footnotetext{
${ }^{3}$ A imagem digital ou imagem de síntese, como discutimos em outro trabalho, diferente da imagem especular produzida pelas técnicas fotográficas ou videográficas, tem sua especificidade marcada pela síntese de imagens, pela produçâo com base em uma matriz numérica manipulável, ou seja, por um programa informático. Sobre isso ver: COSTA, G. C. Tecnologias da Linguagem e a Produção de Imagens Digitais: Formulação e Versão. In: FERREIRA, A. C. F.; MARTINS, R.T. (Orgs.). Linguagem e Tecnologia. 1. ed. Campinas: RG, 2012. p. 69-82.
} 
A discursividade do eletrônico não está nos objetos ou no acesso a eles ou no acesso à internet, ela é um processo histórico e ideológico de significação da nossa sociedade contemporânea, do modo como estamos nela, como praticamos os espaços, do modo como somos interpelados em sujeito pela ideologia, através das determinaçóes históricas (DIAS, 2011, p. 58).

Isso significa que essa discursividade afeta e constitui todo o processo de constituição dos sujeitos e dos sentidos. A escolha de um emoji como palavra do ano reverbera justamente a discursividade do eletrônico, pois realça, pela linguagem, um modo de estar na sociedade contemporânea e suas implicações político-ideológicas.

\section{Emoji: imagem, letra e tecnologia}

Em que ponto a palavra encontra a imagem? Podemos dizer que a distância entre elas não é grande como se poderia imaginar. Entretanto, no que concerne à produção de conhecimento, essa distância tem sido delimitada teoricamente e didaticamente. Nem sempre foi assim, como veremos mais à frente.

É a própria relação entre palavra e imagem que dá origem ao vocábulo emoji, resultado da junção de $e$ (imagem) com moji (letra), na língua japonesa. Outro traço dessa relação é o fato de que os emojis derivam dos emoticons. Moro (2016, p. 8) explica que os "emoticons possuíam apenas a representação do próprio texto, mas, com o tempo, os caracteres foram incorporando imagens gráficas em sua representação e se diversificando de várias maneiras", ou seja, passaram da letra para imagem. Um vestígio do papel desempenhado pela imagem nas condiçóes de produção do discurso eletrônico.

Acerca dessas condiçôes, é relevante frisar, ainda, que os emojis surgem e circulam nas mídias digitais em suas mais diferentes plataformas de comunicação (tablets, smartphones e computadores) como uma grafia característica do discurso eletrônico, ou seja, que pressupóe a ligação com a tecnologia. Eles fazem parte desse discurso. Além disso, passam a compor o campo das coisas-a-saber (PÊCHEUX, 1990) à medida que emoji é dicionarizado e se cria uma enciclopédia para as imagens, cujo funcionamento é o da regulação da interpretação.

Em referência à imagem na articulaçáo com o digital, com o advento de novas tecnologias, a questão da imagem e da captação e projeção de uma situação devem ser consideradas, tendo em vista, por um lado, a forma como 
a imagem digital é produzida, como modifica os modelos de representação do mundo na contemporaneidade. E, por outro lado, levando em conta a nova configuração da imagem em sua maneira de intervir na relação entre o mundo e o homem, à medida que introduz um elemento nessa relaçáo, a saber: a máquina. Nos dois casos, lida-se com a questáo da linguagem, da interpretação, do corpo, da máquina e com o papel por eles representado na construção, projeção e inscrição dos sujeitos nos espaços de significação que resultam de processos da digitalizaçáo e modelização numérica da vida social.

Nesse sentido, não é por acaso que o verbete emoji já foi introduzido em dicionários de diferentes países 4 . Em português, a tradução do termo poderia ser pictograma ou imagem gráfica. Todavia, o que se observa é que a forma da palavra é universalizada, resultando em um efeito do discurso eletrônico, visto que um termo advindo do espaço digital é universalizado. Sendo assim, a questão não é de tradução, mas de definição em seu modo de ser formulada e administrada. Uma questão de significação.

No Dicionário Online de Português, emoji aparece definido simplesmente como imagem:

Significado de Emoji: s.m. Imagem que representa emoçóes, sentimentos, muito usada em aplicativos ou em conversas informais na Internet, embora tenha um significado particular, cada uma é interpretada de acordo com o contexto em que está inserida: alguns emojis (-) (-) :-) :-2) (2)) săo usados de modo muito irônico. [Gramática]Pronuncia-se:/imôdji/ (DICIONÁRIO ONLINE DE PORTUGUÊS, grifos nossos)5.

Historicamente, o dicionário é um espaço de saber no qual se privilegia a palavra. A palavra, há muito tempo, reina absoluta nesse espaço que se configura como "objeto de consulta, que apresenta os significados das palavras com a certitude do saber de um especialista e, eventualmente, com a legitimidade de autores reconhecidos que abonam as definiçóes" (NUNES, 2006, p. 11). No entanto, com a entrada de emoji, a própria forma de descrição em um verbete se textualiza de maneira particular, conforme incorpora a imagem digital, como é o caso acima, pois a exemplificação é

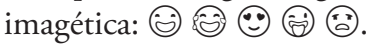

Ao incorporar a palavra emoji, o dicionário incorpora, também, toda uma rede de sentidos advinda da linguagem na relação com a exterioridade.

${ }^{4}$ No Brasil, a palavra foi inserida no Dicionário Online de Português. Em Portugal, no dicionário Priberam. Na França, no Petit Robert.

${ }^{5}$ Verbete disponível em: <http://www.dicio.com.br/emoji/>. Acesso em: 30 jul. 2016. 
Exterioridade essa que "não tem a objetividade empírica do 'fora' da linguagem. Ela é tomada tal como intervém na textualidade. É exterioridade discursiva (e não empírica)" (ORLANDI, 1996, p. 31, grifo da autora). Exterioridade marcada pelo digital.

O fato de um dicionário de língua escolher uma imagem digital em vez de uma palavra, com base em sua relevância social, desconstrói a imaginária primazia da palavra, diminui "aparentemente" o valor atribuído ao saber dos especialistas da língua e valoriza a prática técnica em detrimento do saber desses especialistas. Aponta, portanto, para a linguagem em sua relação com a exterioridade.

A respeito do funcionamento do verbete emoji, do Dicionário Online de Português, nesse contexto, é importante notar que o caráter representativo da imagem é evocado em sua textualidade, um já-dito sobre a imagem se presentifica na definição, aquele que a significa como representação. No verbete em análise, ela é tomada como representação de emoçôes e sentimentos, dizer que marca a dimensão subjetiva do termo. Já o uso dos emojis é dito como restrito às conversas informais na web ou nos apps, isto é, delimita-se um território para os emojis. Além disso, é interessante, também, observar que, no discurso do verbete, o significado dos emojis, ao mesmo tempo em que é anunciado como sendo da ordem do particular, está condicionado ao contexto em que se insere.

O funcionamento do verbete, a partir de sua formulação, aponta para os efeitos do discurso eletrônico sobre a política de língua, porque explicita, ao mesmo tempo, a impossibilidade de se definir o significado de cada emoji, dada a sua universalidade, e condiciona esse significado ao contexto. De um lado, uma discursividade do eletrônico e, de outro, uma discursividade que remete a perspectivas linguísticas, para as quais a concepção de imagem é a da representação, o sentido é visto como determinado pelo contexto e a linguagem é pensada em seu uso.

$\mathrm{Na}$ perspectiva discursiva, esse efeito resulta da não-transparência e da incompletude da linguagem em face da necessidade de se textualizar o emoji, encerrá-lo em uma significação ou outra, contrariando o fato de que o sentido nunca é dado, fixo, imutável, completo. A imagem é tão opaca quanto qualquer outra forma de linguagem, sujeita à falha, ao equívoco. 


\section{Equivalência e Substituição}

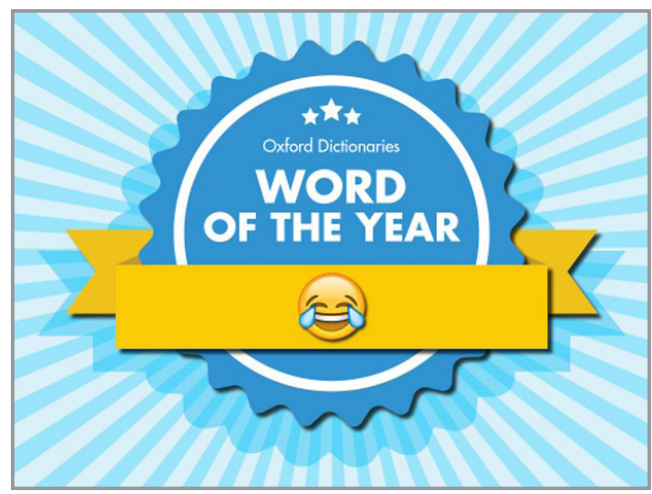

Figura 1: Recorte do blog Oxford Dictionaries. Fonte: Oxford Dictionaries ${ }^{6}$.

Word of the year em seu modo de formular acima, é a discursividade que anuncia o resultado da votação, que, por um lado, textualiza uma relação de equivalência entre word e $e^{3}$, como em uma fórmula $\mathrm{x}=\mathrm{y}$; e, por outro lado, dá a ver a substituição de uma palavra por uma imagem. Efeitos do equívoco como "falha da língua inscrita na história" (ORLANDI, 2001, p. 9).

$\mathrm{Na}$ instância do equívoco, tanto a equivalência quanto a substituição produzem sentido, pois, de acordo com Pêcheux (1988, p. 263), "o sentido existe nas relaçóes de metáfora (realizadas em efeitos de substituição, paráfrases, formaçóes de sinônimos)", ou seja, em um processo discursivo. Nessa perspectiva, o jogo entre word e , a partir da relaçáo de equivalência, rompe o limite estabelecido historicamente entre o que se convencionou chamar de linguagem verbal e não-verbal, palavra e imagem, vendo, na segunda, a complementaridade da primeira, pois, nesse caso, a equivalência aponta para a indistinçáo entre uma e outra. Como efeito, um deslocamento é produzido, ou melhor, desloca-se o sentido estabilizado de palavra e de imagem que as diferencia. Assim ele é posto em xeque.

Em outra via, esse jogo nos permite perguntar: a imagem se configuraria como a palavra que se escreve, lê-se, vê-se, porém não se pronuncia?

Disponível em: <http://blog.oxforddictionaries.com/2015/11/word-of-the year 2015-emoji/>. Acesso em: 30 jul. 2016. 
Tomando tanto a palavra como a imagem como formas gráficas, poderíamos também considerar a atualização da escrita pictográfica a partir dessa substituição. Poderíamos, assim, dizer que o discurso eletrônico atualiza essa escrita, confere outros contornos a ela, pois, em vez do desenho, da mão, da pedra, estão a imagem digital, o computador e a tela. Em comum, mas diferente, o corpo.

A partir da relação de substituição, investida nesse mesmo jogo entre word e está a possibilidade de marcar de uma maneira específica o corpo do sujeito no corpo da linguagem, a corporeidade, que Orlandi (2001) atribui à prática do corpo que se corporifica no textual. Ou, ainda, explicita a corpografia, isto é, o "modo como o corpo se inscreve materialmente na língua” (DIAS, 2008, p. 12), pensando a inscriçáo do corpo na forma da grafia $^{7}$. A pesquisa de Dias, que resulta na noção de corpografia, reflete sobre a escrita do internetês, incluídos aí os emoticons e os emojis; sobre o modo como essa escrita está investida numa relação com o corpo do sujeito, com seus afetos e laços de pertencimento, provocando a transgressão do sistema de representação da língua.

\section{A emojipedia e a contençáo dos sentidos}

Resulta da exterioridade constitutiva da linguagem outro objeto de saber, criado a partir dos emojis, cujo discurso - assim como o do dicionário - tende a estabilizar sentidos. Trata-se da emojipedia, espécie de enciclopédia virtual que se propóe a apresentar, descrever e explicar o significado dos mais variados emojis. Além disso, essa enciclopédia disponibiliza as diferentes versôes dos emojis de acordo com as plataformas em que ele foi reproduzido.

A pergunta que fazemos aqui é: como se define o sentido de emojis, tais como , eleito a palavra do ano? O dicionário Oxford o define a partir da descrição: "face with tears of joy". Encontramos essa mesma descrição em português: "rosto com lágrimas de alegria". Encontramos também "Emoji

\footnotetext{
${ }^{7}$ Essa pesquisa pode ser conferida além da referência citada em: DIAS, C. A língua em sua materialidade digital. In: $\mathrm{O}$ discurso na contemporaneidade: materialidades $\mathrm{e}$ fronteiras. Sáo Carlos: Clara Luz, 2009. p. 83-92. DIAS, C. Sujeito, sociedade e tecnologia: a discursividade da rede (de sentidos). São Paulo: Hucitec, 2012.

8 Ver em: <http://blog.oxforddictionaries.com/2015/11/word-of-the-year-2015-emoji/>. Acesso em: 30 jul. 2016.

${ }_{9}$ Disponível em: <http://g1.globo.com/educacao/noticia/2015/11/emoji-e-eleito-pela-1-vezpalavra-do-ano-pelo-dicionario-oxford.html>. Acesso em: 30 jul. 2016.
} 
que representa coisas: chorando de rir ou de alegria"10, além do modo de se definir nomeando o emoji: "Emoji morrendo de rir", como abaixo:

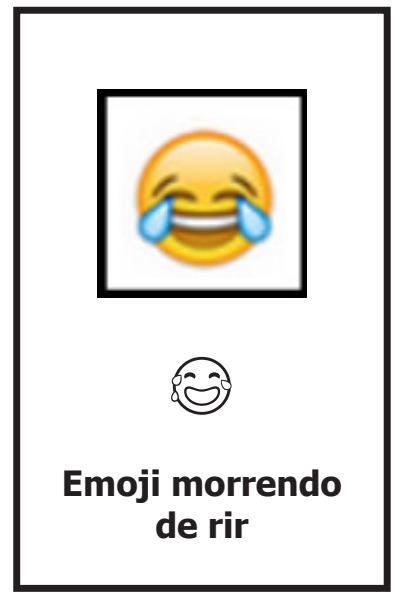

Figura 2: Recorte da web.

Fonte: Dicas do Pita ${ }^{11}$.

$\mathrm{Na}$ emojipedia, a textualidade é a seguinte:

()) Face With Tears of Joy

A laughing emoji which at small sizes is often mistaken for being tears of sadness. This emoji is laughing so much that it is crying tears of joy.

O emoji é acompanhado pela expressão "Face Whith Tears of Joy", como se fosse tanto seu nome como seu significado. Na sequência, aparece uma explicação, o emoji muitas vezes é confundido em tamanho menor com lágrimas de tristeza, mas as lágrimas são de alegria, por rir muito, ele chega a chorar. Observa-se aí a tentativa de fixar uma interpretação. Poderíamos parafrasear esse dizer da seguinte maneira: Atenção, não se trata de lágrimas de tristeza. Esse emoji significa alegria.

As possibilidades de se nomear e/ou significar esse emoji são

${ }^{10}$ Disponível em: <http://www.redetv.uol.com.br/jornalismo/tecnologia/pela-1-vez-emoji-eeleito-a-palavra-do-ano-pelo-dicionario-oxford>. Acesso em: 30 jul. 2016.

11 Disponível em: <https://dicasdopita.com.br/blog/variedades-3/post/emojis-para-copiar-ecolar-nas-redes-sociais-53>. Acesso em: 30 jul. 2016. 
antecedidas por "também conhecido como", uma forma de dizer: também pode significar isso. Na sequência, essas possibilidades são agrupadas em torno dos verbos rir e chorar (rindo, rindo chorando, lágrimas de riso, gargalhada), como mostramos abaixo:

\section{Also Known As}

\section{Laughing Emoji}

\section{Laughing Crying Emoji}

\section{Laughing Tears Emoji}

\section{LOL Emoji}

Figura 3: Recorte da emojipedia.

Fonte: Emojipedia ${ }^{12}$.

Há uma tentativa de eliminar outras possibilidades de interpretação, de controlar a polissemia, enquanto "pluralidade de movimentos de sentido" (ORLANDI, 2012b, p. 25) que incide sobre o par rir-chorar, lágrimas de alegria-lágrimas de tristeza, riso-choro. Essa tentativa é uma regularidade do funcionamento da emojipedia que tem efeitos na sociedade, visto que produz discursos sobre "os verdadeiros significados" dos emojis, como no caso abaixo, em que se pressupóe que o usuário tenha usado o emoji com outro significado, ao mesmo tempo em que se aponta, a partir da expressão aspada 'entendeu errado', para um discurso-outro que náo aquele do erro.

"Dez emojis que você 'entendeu errado' e usou com outro significado"13.

\footnotetext{
${ }^{12}$ Disponível em: <http://emojipedia.org/face-with-tears-of-joy/>. Acesso em: 30 jul. 2016.

${ }^{13}$ Título da reportagem de Gabriella Fiszman para o TechTudo. Disponível em: <http://www. techtudo.com./listas/noticia/2015/05/dez-emojis-que-voce-entendeu-errado-e-usou-comoutro-significado-veja.html>. Acesso em: 30 jul. 2016.
} 
Assim, poderíamos brevemente dizer que, em face da tentativa de controle da polissemia, esse discurso-outro, em contrapartida, dá visibilidade justamente ao movimento polissêmico, à opacidade da linguagem.

Nesse ponto de nossa reflexão, é importante fazer referência à análise de Ferreira (2012), em que a autora discorre sobre as enciclopédias virtuais, situando-as, como artefatos da mídia na internet, no campo da produção e gestão do conhecimento face à relação dos sujeitos com os saberes. Com isso, enfatizamos o fato de que a emojipedia circula em inglês e retomamos, ainda, o que dizíamos acima sobre a relação entre o discurso do digital e do multilinguismo. Isso porque a emojipedia se apropria dos emojis, atuando na administração de seus sentidos, mediando a relação dos sujeitos com os saberes em uma língua específica.

O processo instaurado, nesse caso, é o da anglofonização dos sentidos da imagem. Os emojis circulam no mundo todo, mas são significados diferentemente pelos sujeitos. Todavia, a instituição da emojipedia trabalha na contençáo de seus sentidos. Com isso, os sentidos passam a ser geridos por esse instrumento, cuja língua é o inglês, a língua do poder, a que "tem as reais condiçốes de se impor, de se instrumentar, de concretizar relaçóes entre os 'falantes' (usuários?) de diferentes partes do mundo", conforme analisa Orlandi (2012a, p. 8). Esse gesto de apropriaçáo se configura em meio ao discurso do multilinguismo.

Em seu estudo, Orlandi (2012a) assevera que:

\begin{abstract}
Não podemos deixar de observar que há, contemporaneamente, um grande investimento no discurso do multilinguismo que se acompanha, fortemente, do discurso da mundializaçáo/globalização. Ao contextualizá-lo em relação à globalização já estamos significando de uma maneira específica as línguas em suas relações. Essa formação ideológica da globalização, a que se agrega o multilinguismo, se constitui de uma contradição entre seu discurso formal universalizante e sua prática concreta de segregação. É uma formação ideológica que, frequentemente, produz a reduçấo das culturas a museus, museifica as relaçóes com línguas locais, se prende a um multiculturalismo empobrecedor, que faz idealmente a apologia da diferença e da multiplicidade, mas impóe, na prática, um monolinguismo fechado que silencia a pluralidade linguística necessária à dinâmica das sociedades e dos sujeitos no mundo (ORLANDI, 2012a, p. 7).
\end{abstract}

A anglofonização do emoji é um recorte do multilinguismo que, na prática, náo passa de um efeito funcionando a favor do monolinguismo, da administração dos sentidos, da regulação da interpretação. 
Indo além, o efeito de anglofonização resulta de uma tentativa de contenção dos sentidos, de regulação da interpretação em prol de um processo de manutenção da língua da tecnologia, e isso se dá em uma conjuntura em que a imagem ganha uma nova configuração e ocupa cada vez mais o espaço digital. Com isso, poderíamos pressupor que a dicionarizaçáo do termo emoji, a seleção de uma imagem digital e a anglofonização do emoji são vestígios de uma política de contenção da expansão de uma linguagem do digital que não seria de domínio de um idioma ou outro?

\section{Dos efeitos produzidos}

Orlandi (2009) afirma que o discurso eletrônico incide sobre a vida intelectual, reorganizando e redistribuindo os lugares de interpretação e, com isso, produz diversos deslocamentos na qualidade de tecnologia de escrita. Dias $(2008 ; 2009 ; 2012)$ corrobora essa afirmação, sobretudo, com a análise da corpografia e com a reflexão sobre o digital. A compreensão que apresentamos aqui, inspirada pelos trabalhos dessas duas autoras, visou, à sua maneira, discutir um dos modos do discurso eletrônico funcionar a partir da relação com a produção de imagens e com a configuração de dispositivos que inauguram novas formas de se lidar com a imagem digital, com a escrita e com o próprio modo de significar o mundo.

Nessa direçáo, tomando como ponto de partida a análise de discursividades em torno da palavra do ano, foi possível observar a forma como o discurso eletrônico produz deslocamentos em relação aos sentidos, tanto de palavra quanto de imagem, ao passo que ressignifica a própria palavra "palavra" - pois esta poderia nomear qualquer coisa que "comunique" e que possa ser escrita em um editor de texto de dispositivo digital - e rompe com o limite entre o que se convencionou chamar e apartar de linguagem verbal e não-verbal.

Em paralelo, a análise nos permitiu observar a produção do efeito de anglofonização pela emojipedia, cujo funcionamento constitui um processo de manutenção da língua da tecnologia. E, ainda, possibilitou-nos - por meio da tentativa de se textualizar e, dessa forma, significar o emoji, regulando sua interpretação - dar visibilidade e, assim, ratificar que "tudo não se diz" e que "sempre faltam palavras para dizer alguma coisa" (MILNER, 1975, p. 44), já que a incompletude e não-transparência da linguagem mantêm uma incontornável relação com a história, a política e a ideologia. 


\section{Referências}

AUROUX, Sylvain. A revoluçáo tecnológica da gramatizaçáo. Trad. Eni P. Orlandi. Campinas: Unicamp, 1992.

COSTA, Greciely Cristina. Tecnologias da Linguagem e a Produção de Imagens Digitais: Formulação e Versão. In: FERREIRA, Ana Cláudia Fernandes; MARTINS, Ronaldo Teixeira (Orgs.), Linguagem e Tecnologia. 1. ed.Campinas: RG, 2012. p. 69-82.

DIAS, Cristiane. Da corpografia: ensaio sobre a língua/escrita na materialidade digital. Santa Maria: UFSM-PPGL, 2008.

. A língua em sua materialidade digital. In: O discurso

na contemporaneidade: materialidades e fronteiras. São Carlos: Clara Luz, 2009. p. 83-92.

. Cidade, cultura e corpo: a velocidade do mundo. Escritos, n. 10. Campinas: Labeurb/Nudecri/Unicamp, 2011. Disponível em:

$<$ http://www.labeurb.unicamp.br/portal/pages/pdf/escritos/Escritos10.pdf >. Acesso em: jan. 2017.

Sujeito, sociedade e tecnologia: a discursividade da rede (de sentidos). São Paulo: Hucitec, 2012.

FERREIRA, Ana Cláudia Fernandes. As coisas-a-saber sobre uma cidade na Wikipédia e na Desciclopédia: Pouso Alegre entre edifícios e buracos. RUA, n.18, p. 35-58. 2012.

MILNER, Jean Claude. O amor da língua. Porto Alegre: Artes Médicas, 1987.

MORO, Gláucio Henrique Matsushita. A Pictografia, Relaçóes Culturais e Tecnológicas: a iconografia digital como modelo de comunicação em interfaces. In: Intercom - Sociedade Brasileira de Estudos Interdisciplinares da Comunicaçáo - XVII Congresso de Ciências da Comunicação na Regiâo Sul. Curitiba, PR - 26 a 28/05/2016. Disponível em: <http://www.portalintercom.org.br/anais/sul2016/resumos/R501602-1.pdf $>$. Acesso em: 30 jul. 2016.

NUNES, José Horta. Dicionários no Brasil: análise e história do século XVI ao XX. Campinas: Pontes, 2006. 
ORLANDI, Eni Puccinelli. Discurso, imaginário social e conhecimento. Em aberto, v. 14, n. 61, p. 52-59. 1994.

. Exterioridade e ideologia. Cadernos de Estudos linguísticos, n. 30, p. 27-33. 1996.

Discurso e texto: formulação e circulação dos sentidos. Campinas: Pontes, 2001.

. O que é linguística. 2. ed. São Paulo: Brasiliense, 2009.

. Espaços Linguísticos e seus desafios: convergências e divergências. RUA. n. 18, p. 5-18. 2012a.

- Sentidos em fuga: efeitos da polissemia e do silêncio. In: CARROZZA, Guilherme; SANTOS, Mirian dos; SILVA, Telma Domingues da (Orgs.). Sujeito, Sociedade, Sentidos. Campinas: RG, 2012b. p. 11-27. PÊCHEUX, Michel. Semântica e discurso: uma crítica à afirmação do óbvio. Campinas: Unicamp, 1988.

. O discurso: estrutura e acontecimento. Campinas: Pontes, 1990.

. Ler o arquivo hoje. In: ORLANDI, Eni Puccinelli (Org.), Gestos

de leitura: da história no discurso. Campinas: Unicamp, 1994. p. 55-66.

Análise automática do discurso. In: GADET, F.; HACK, T. (Orgs.). Por uma análise automática do discurso: uma introdução à obra de Michel Pêcheux. 3. ed. Campinas: Unicamp, 1997. p. 61-161.

A aplicação dos conceitos da linguística para a melhoria das técnicas de análise de conteúdo. In: Análise de Discurso: Michel Pêcheux. Textos selecionados por Eni Puccinelli Orlandi. Campinas: Pontes, 2011. p. 203-226. 